\title{
PROFIL FARMAKOKINETIKA SIMETIDIN
}

\author{
Ni Made Sesari Aswinda ${ }^{1, *}$, Risna Agustina ${ }^{1}$, Rolan Rusli ${ }^{1,2, \dagger}$ \\ ${ }^{1}$ Laboratorium Penelitian dan Pengembangan Kefarmasian "Farmaka Tropis", \\ Fakultas Farmasi, Universitas Mulawarman, Samarinda \\ ${ }^{*}$ Email : nimadesesariaswinda@yahoo.com \\ ${ }^{2}$ Kelompok Bidang Ilmu Kimia Farmasi, Fakultas Farmasi, \\ Universitas Mulawarman, Samarinda \\ †Email: rolan@farmasi.unmul.ac.id
}

\begin{abstract}
ABSTRAK
Penelitian ini dilakukan untuk mengetahui profil farmakokinetika simetidin pada tikus putih putih jantan. Cuplikan darah hewan coba diambil pada menit ke 0, 15, $30,45,60,75,90,120,150,180,210$, dan 240 melalui vena lateralis ekor tikus. Penetapan kadar simetidin dalam plasma dilakukan menggunakan metode spektrofotometer $U V$-Visible pada panjang gelombang 220,2 $\mathrm{nm}$. Parameter farmakokinetika simetidin dihitung menggunakan persamaan regresi linear sehingga diperoleh nilai $K_{a} 0,0488$ menit $^{-1} ; K 0,0031$ menit $^{-1} ; t_{1 / 2} 232,65$ menit; $t_{\text {maks }}$ 88,90 menit; $C p_{\text {maks }}$ 0,9943 mcg/mL; AUC 314,2746 mcg/menit.mL; $V_{d} 3143,048$ $\mathrm{mL} / \mathrm{gBB}$ dan $C l_{T} 10,1522 \mathrm{~mL} / \mathrm{menit} \mathrm{g}$.
\end{abstract}

Kata kunci: simetidin, farmakokinetik, spektrofotometer

\begin{abstract}
The aim of this study is to observe pharmacokinetic profile of cimetidine in male white rats. Blood sampling was taken from lateralist vena at rat tail at $0,15,30$, $45,60,75,90,120,150,180,210$, and 240 minute. The cimetidine content in blood was measured by spectrophotometer UV-Visible method at $220 \mathrm{~nm}$. Pharmacokinetic parameters of cimetidine was calculated by regresi linear method and the result were $K_{a} 0.0488$ minute $^{-1} ; K 0.0031$ minute $^{-1} ; t_{1 / 2} 232.65$ minute; $t_{\text {maks }}$ 88.90 minute; $C p_{\text {maks }} 0.9943 \mathrm{mcg} / \mathrm{mL}$; AUC $314.2746 \mathrm{mcg} /$ minute. $\mathrm{mL} ; V_{d} 3143.048$ $\mathrm{mL} / \mathrm{gBB}$; and $\mathrm{Cl}_{T} 10.1522 \mathrm{~L} / \mathrm{minute} \mathrm{g}$.
\end{abstract}

Keywords: cimetidine, pharmacokinetic, spectrophotometer 


\section{PENDAHULUAN}

Ulkus peptikum merupakan ulkus kronik yang secara khas bersifat soliter dan timbul karena pajanan sekresi lambung yang asam [1]. Komplikasi penyakit ulkus peptikum ditemukan pada 10\%-20\% dari jumlah pasien dan sekitar 2\%-14\% pasien mengalami ulkus peptikum perforasi (PPU) [2]. Simetidin adalah salah satu obat yang dapat digunakan dalam terapi ulkus peptikum atau tukak lambung. Simetidin merupakan obat golongan antagonis $\mathrm{H}_{2}$-reseptor (histamin) yang menghambat secara kompetitif terhadap reseptor histamin di sel-sel pariental lambung dan atrium jantung $\left(\mathrm{H}_{2}\right.$-reseptor) [3].

Efek farmakologis dan efek toksik suatu obat seringkali dikaitkan dengan konsentrasi obat dalam plasma. Tanpa adanya data farmakokinetika, maka konsentrasi obat dalam plasma tidak berguna. Kajian mengenai farmakokinetika obat sangat penting dilakukan untuk mengetahui profil obat dalam tubuh sehingga penyesuaian dosis dapat dilakukan untuk mengoptimasi terapi yang diberikan. Ilmu farmakokinetik merupakan ilmu yang mempelajari bagaimana nasib yang dialami obat di dalam tubuh, mulai dari proses absorbsi, distribusi, metabolisme, dan eksresi (ADME), yang diterangkan secara kuantitatif melalui rumus-rumus yang diperoleh dari manipulasi matematik [4].Fase farmakokinetika simetidin meliputi proses metabolisme yang terjadi sekitar $30 \%$ oleh hati dan sisanya dikeluarkan tanpa perubahan oleh ginjal [5].

Penelitian ini diharapkan dapat memberikan informasi mengenai profil farmakokinetika simetidin melalui perhitungan parameter-parameter farmakokinetikanya.

\section{METODE PENELITIAN}

\section{Hewan Coba}

Hewan coba yang digunakan adalah tikus putih jantan galur Wistar dengan berat badan 180-250 g.

\section{Bahan}

Bahan yang digunakan adalah simetidin (Sigma-Aldrich, 51481-61-9); etil asetat; etilen diamin tetra asetat (EDTA); asam trikloroasetat (TCA); metanol; akuades; dan $\mathrm{NaOH}$.

\section{Peralatan}

Peralatan yang digunakan adalah peralatan gelas yang meliputi gelas kimia $50 \mathrm{~mL}, 100 \mathrm{~mL}, 250 \mathrm{~mL}$, dan $500 \mathrm{~mL}$; labu takar $10 \mathrm{~mL}, 25 \mathrm{~mL}, 50 \mathrm{~mL}$, dan 100 $\mathrm{mL}$; corong kaca; pipet ukur $5 \mathrm{~mL}$ dan $10 \mathrm{~mL}$; tabung reaksi; alat instrumen Spektrofotometer UV-Visible double beam (HALO DB 20S) dan Oven; blender; spoit $3 \mathrm{~mL}$, tabung effendrof, vorteks, mikropipet 100-1000 $\mu \mathrm{L}$, dan sentifuge. 


\section{Prosedur}

\section{Penentuan Panjang Gelombang Maksimum Simetidin}

Penentuan panjang gelombang maksimum simetidin dilakukan dengan menggunakan larutan baku simetidin dengan kadar 200 ppm dan diukur serapannya pada panjang gelombang $200 \mathrm{~nm}$ sampai $250 \mathrm{~nm}$.

\section{Kurva Baku Simetidin}

Pembuatan kurva baku simetidin dilakukan dengan menimbang baku simetidin sebanyak $10 \mathrm{mg}$ dan dilarutkan dengan $1 \mathrm{~mL}$ metanol dalam ditambahkan aquades hingga $50 \mathrm{~mL}$ dan diperoleh larutan induk baku simetidin dengan kadar 10 $\mathrm{mg} / 50 \mathrm{~mL}$ atau setara dengan $200 \mathrm{ppm}$. Dari larutan induk tersebut dibuat variasi konsentrasi sebesar 2,5 ppm; 5 ppm; 7,5 ppm; 10 ppm; dan 12,5 ppm.

\section{Penetapan Profil Farmakokinetika Simetidin}

Dipuasakan tikus jantan galur Wistar selama 8 jam kemudian diberikan larutan simetidin dosis $3,6 \mathrm{mg} / 200 \mathrm{gBB}$ secara oral. Cuplikan darah diambil pada menit ke $0,15,30,45,60,75,90,120,150,180,210$, dan 240 melalui vena lateralis ekor tikus. Cuplikan darah ditampung pada tabung effendrof yang telah berisi larutan EDTA 10\%. Kemudian ditambahkan TCA 5\% dan disentrifugasi dengan kecepatan 3000 rpm selama 10 menit. Diambil plasma darah dan ditambahkan $\mathrm{NaOH}$ dan etil asetat, kemudian divorteks. Diambil lapisan etil asetat, diuapkan pada suhu $60^{\circ} \mathrm{C}$ hingga diperoleh residu. Dilarutkan residu simetidin dengan $1 \mathrm{~mL}$ metanol dan ditambahkan dengan $9 \mathrm{~mL}$ akuades. Diukur absorbansi simetidin dengan spektrofotometer $U V$-Visible pada panjang gelombang 220,2 nm. Kadar simetidin dalam darah dihitung menggunakan persamaan regresi linier kurva baku.

\section{HASIL DAN PEMBAHASAN}

\section{Panjang Gelombang Maksimum Simetidin}

Penentuan panjang gelombang maksimum simetidin dilakukan menggunakan larutan variasi konsentrasi simetidin $2,5 \mathrm{ppm}$ dalam rentang panjang gelombang 200-250 nm. Panjang gelombang maksimum simetidin diperoleh sebesar 220,2 nm seperti terlihat pada Gambar 1. Panjang gelombang tersebut digunakan dalam setiap pembacaan absorbansi simetidin pada penetapan kadar simetidin selanjutnya.

\section{Kurva Baku Simetidin}

Kurva baku menggambarkan hubungan antara kadar dan serapan yang diperoleh dari analisis regresi data kadar terhadap serapan. Analisis regresi ditunjukkan pada Gambar 2 dengan persamaan regresi $y=0,1867 x-0,0475$ dengan nilai $\mathrm{r}=0,9969$, dimana $\mathrm{x}$ menyatakan kadar obat (ppm) dan y menyatakan serapan atau absorbansi (A). Kurva baku simetidin ditunjukkan pada Gambar 2. 


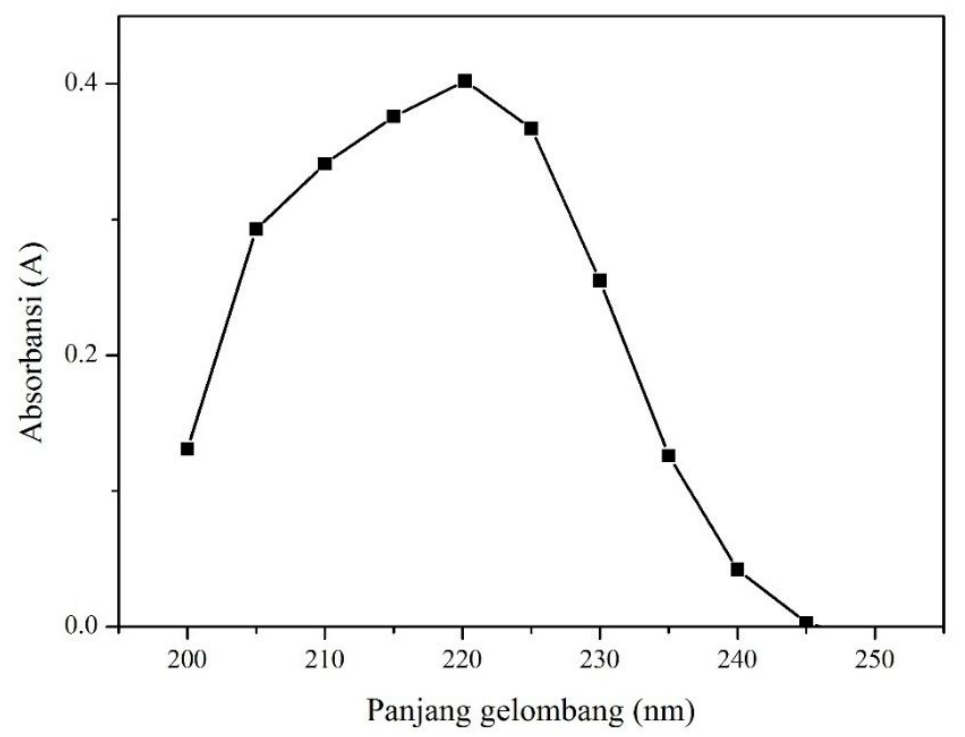

Gambar 1. Kurva hubungan absorbansi terhadap panjang gelombang simetidin

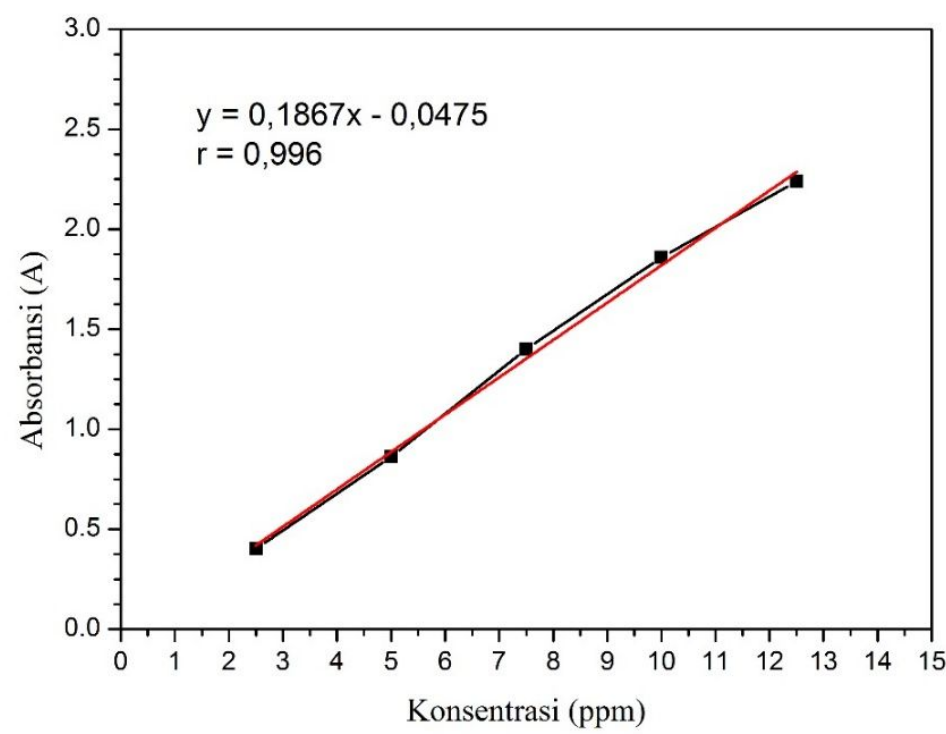

Gambar 2. Kurva garis regresi linear hubungan antara kadar simetidin (ppm) dan serapan atau absorbansi (A)

Harga koefisien korelasi (r) yang mendekati 1 dari kurva baku menunjukkan korelasi antara konsentrasi (x) dan absorbansi (y) yang telah sesuai dengan Hukum Lambert-Beer, dimana nilai absorbansi berbanding lurus dengan nilai konsentrasi. 


\section{Profil Farmakokinetika Simetidin}

Penentuan profil farmakokinetika simetidin dilakukan menggunakan 3 hewan uji, dimana diambil cuplikan darah melalui vena lateralis pada ekor tikus kemudian cuplikan darah yang telah diperoleh dipreparasi sesuai dengan prosedur penentuan profil farmakokinetika simetidin. Kemudian diukur absorbansi simetidin dan dihitung kadarnya menggunakan persamaan regresi linear kurva baku simetidin. Kadar simetidin pada plasma darah masing-masing hewan uji dan profil farmakokinetika simetidin ditunjukkan pada Gambar 3.

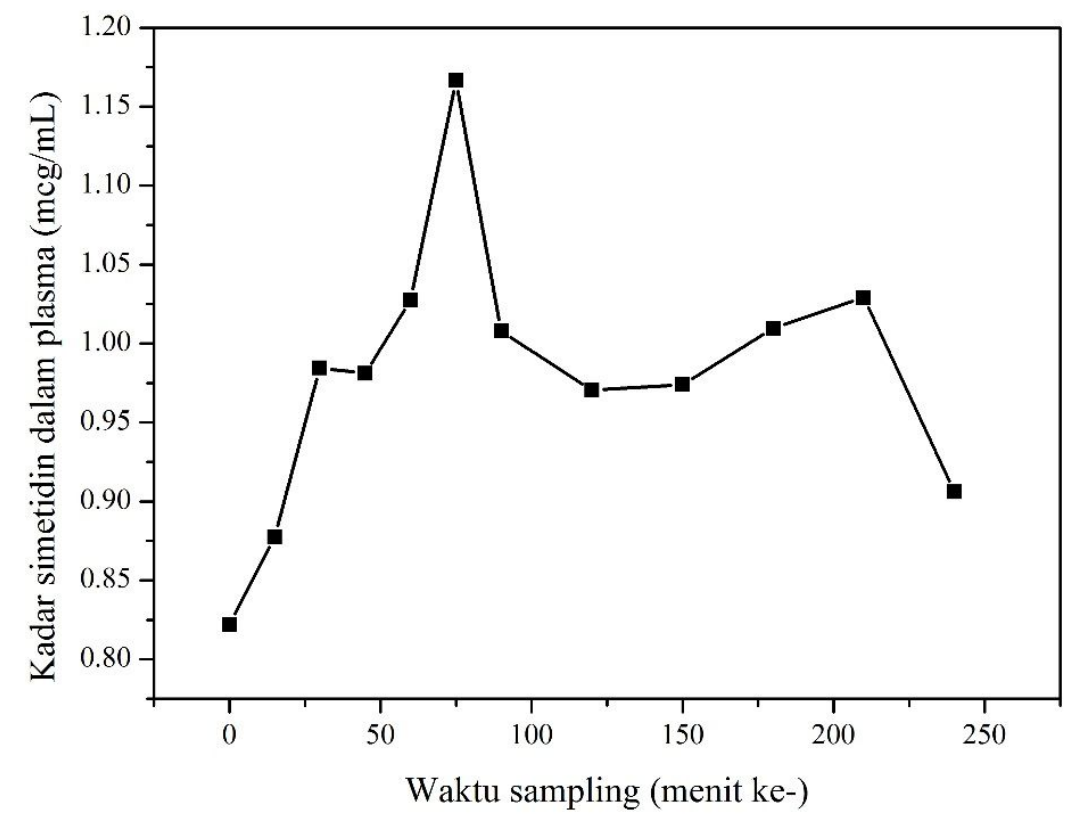

Gambar 3. Kurva profil farmakokinetika simetidin

Berdasarkan profil farmakokinetika simetidin tersebut dapat diketahui parameter-parameter farmakokinetika simetidin yang ditunjukkan pada Tabel 3 . Parameter farmakokinetika ditetapkan menggunakan metode residual. Fase absorbsi dapat ditentukan melalui nilai $K_{a}, C_{m a k s}, T_{m a k s}$, dan $A U C$. Nilai $K_{a}$ yang diperoleh lebih besar daripada nilai $K$, yang menunjukkan bahwa jumlah simetidin yang diabsorbsi pada waktu-waktu awal lebih besar daripada jumlah simetidin yang dieliminasi. Kadar simetidin dalam plasma pada fase absorbsi akan terus meningkat hingga mencapai kadar puncak $\left(C_{\text {maks }}\right.$ ) yaitu $0,9943 \mathrm{mcg} / \mathrm{mL}$, dimana pada kadar puncak ini kecepatan absorbsi sama dengan kecepatan eliminasi dan waktu yang dibutuhkan untuk mencapai kadar puncak $\left(t_{m a k s}\right)$ terjadi pada menit ke 88,90 . Nilai $A U C$ menggambarkan jumlah simetidin yang diabsorbsi dari sejumlah dosis 
simetidin yang diberikan, yakni 314,2476 $\mathrm{mcg} /$ menit.mL simetidin yang diabsorbsi tiap menitnya pada tiap $\mathrm{mL}$ darah.

Tabel 3. Nilai parameter farmakokinetika simetidin

\begin{tabular}{lc}
\hline \multicolumn{1}{c}{ Parameter Farmakokinetika } & Nilai Parameter \\
\hline$K$ (menit $\left.^{-1}\right)$ & 0,0031 \\
$K_{a}$ (menit $\left.^{-1}\right)$ & 0,048833 \\
$T_{\text {maks }}\left(\right.$ menit $^{-1}$ & 88,90577 \\
$C p_{\text {maks }}(\mathrm{mcg} / \mathrm{mL})$ & 0,994367 \\
$V_{d}(\mathrm{~mL} / \mathrm{gBB})$ & 3143,048 \\
$C_{T}(\mathrm{~mL} / \mathrm{menit})$ & 10,15227 \\
$t_{1 / 2}(\mathrm{menit})$ & 232,65 \\
$A U C_{\infty}^{0}(\mathrm{mcg} /$ menit.mL $)$ & 314,2746 \\
\hline
\end{tabular}

Fase distribusi digambarkan melalui nilai $V_{d}$, yang merupakan besarnya distribusi simetidin di dalam tubuh. $V_{d}$ berbanding terbalik dengan konsentrasi obat dalam plasma, dimana dengan meningkatnya $V_{d}$ maka konsentrasi obat dalam plasma menjadi kecil dan juga sebaliknya. Sementara fase eliminasi dapat digambarkan melalui nilai parameter $K, t_{1 / 2}$, dam $C_{T}$. Nilai tetapan kecepatan eliminasi $(K)$ yang diperoleh menunjukkan laju penurunan kadar obat setelah proses farmakokinetika mencapai kesetimbangan, yaitu 0,0031 per menit. Kadar simetidin dalam plasma akan berkurang menjadi setengahnya (waktu paruh) pada menit ke 232,65 . Waktu paruh dapat digunakan untuk menentukan interval pemberian obat untuk mencegah akumulasi yang membahayakan dan ketiadaan obat di dalam darah. Pada penentuan profil farmakokinetika simetidin ini jumlah darah total yang terbersihkan dari obat $\left(\mathrm{Cl}_{T}\right)$ adalah $10,1522 \mathrm{~mL}$ tiap menitnya.

\section{KESIMPULAN}

Profil farmakokinetika simetidin diketahui berdasarkan nilai parameterparamater farmakokinetika simetidin yang meliputi nilai $K_{a} 0,0488$ menit $^{-1} ; K$ 0,0031 menit $^{-1} ; t_{1 / 2} 232,65$ menit; $t_{\text {maks }} 88,90$ menit; $C p_{\text {maks }} 0,9943 \mathrm{mcg} / \mathrm{mL} ; A U C$ $314,2746 \mathrm{mcg} / \mathrm{menit} . \mathrm{mL} ; V_{d} 3143.048 \mathrm{~mL} / \mathrm{gBB}$ dan $\mathrm{Cl}_{T} 10,1522 \mathrm{~mL} / \mathrm{menit} \mathrm{g}$.

\section{DAFTAR PUSTAKA}

[1] Richard, N., dan Mitchell. 2008. Buku Saku Dasar Patologis Penyakit Robbins \& Cotran Edisi 7. EGC: Jakarta.

[2] Thorsen, Kenneth. et al. 2013. Epidemiology of Perforated Peptic Ulcer: Age and Gender Adjusted Analysis of Insidence and Mortality. World Journal of Gastroenterology. 19(3). 347-354.

[3] Schmitz, Gery. Lopper, H. Heidrick, Michael. 2008. Farmakologi dan Toksikologi Edisi Ketiga. EGC: Jakarta. 
[4] Hakim, Lukman. 2010. Farmakokinetik. Bursa Ilmu: Yogyakarta.

[5] Deglin, Judith Hopfer. 2004. Davis's Drug Guide For Nurses. EGC: Jakarta. 